\title{
A demissão dos religiosos por ausência ilegítima da casa religiosa após o motu proprio Communis Vita (Parte I)
}

\author{
The Dismissal of Religious Relatives for the Illegitimate Absence of \\ the Religious House after Motu Proprio Communis Vita \\ (Pars I)
}

\section{Valdinei de Jesus Ribeiro ${ }^{1}$}

Resumo: A ausência ilegítima da casa religiosa é uma razão suficiente para que um religioso seja demitido do instituto, uma vez que a vida comunitária é um dos elementos centrais da consagração religiosa. Até março de 2019, o cumprimento das exigências processuais para a demissão de um religioso pelo motivo aludido encontrava certa dificuldade quando não era possível localizá-lo. Para superar o problema, o Papa Francisco publicou o motu proprio Communis Vita, com o qual fez alguns acréscimos ao cân. 694 do CIC atual, determinando que, a partir de sua entrada em vigor, a ausência ilegítima nos termos fixados
Abstract: The illegitimate absence of the religious house is a sufficient reason for a religious to be dismissed from the institute, since community life is one of the central elements of religious consecration. Until March 2019, compliance with the procedural requirements for the dismissal of a religious for the reason mentioned had some difficulty when it was not possible to locate him. To overcome the problem, Pope Francis published the motu proprio Communis Vita, with which he made some additions to can. 694 of the current CIC, stating that, upon its entry into force, the illegitimate absence under the terms of the standard

1 Valdinei de Jesus Ribeiro. Doutor e Mestre em Utroque Iure (Direito Canônico e Civil) pela Pontifícia Universidade Lateranense (Cidade do Vaticano) - título convalidado no Brasil pela PUC-RJ. Especialista em Counseling (Aconselhamento) pelas Faculdades Bagozzi de Curitiba-PR. Graduado em Filosofia pelo Centro Universitário Claretiano de Batatais e em Teologia pela Pontifícia Universidade Salesiana de Roma. Atualmente é professor do Instituto Superior de Direito Canônico Santa Catarina em Florianópolis (SC) e colabora com o Pontifício Instituto Superior de Direito Canônico do Rio de Janeiro - extensão Londrina (PR). É professor da Faculdade Claretiana de Teologia (Studium Theologicum) em Curitiba (PR) e Vigário Judicial Adjunto do Tribunal Eclesiástico Interdiocesano e de Apelação de Curitiba (PR).

E-mail:<vjribeiro@brturbo.com.br>. 
pela norma seja causa de demissão ipso facto, simplificando, assim, o procedimento a ser adotado. É preciso, então, refletir sobre o tema, uma vez que, a partir de agora, há dois modos distintos de se demitir um religioso pela mesma causa, embora com algumas variantes, uma vez que o quanto previsto pelo cân. 696 não sofreu qualquer tipo de alteração. Isso significa afirmar que, na prática, a demissão de um religioso por ausência ilegítima poderá se dar pela via da demissão $a b$ homine facultativa (primeira parte do artigo) ou pela via da demissão ipso facto (segunda parte do artigo).

Palavras Chave: Ausência ilegítima; demissão $a b$ homine facultativa; semissão ipso facto; procedimento. is cause for dismissal ipso facto, thus simplifying the procedure to be adopted. It is then necessary to reflect on the subject, since, from now on, there are two distinct ways of dismissing a religious for the same cause, albeit with some variations, since as provided for in can. 696 has not changed at all. This means that, in practice, the dismissal of a religious for illegitimate absence may be by means of the optional $a b$ homine dismissal (first part of the article) or via the ipso facto dismissal (second part of the article).

Keywords: Illegitimate absence; Optional $a b$ homine dismissal; Dismissal ipso facto; Procedure.

\section{Introdução}

O Papa Francisco, aos 19 de março de 2019, publicou uma Carta Apostólica na forma de motu proprio, intitulada Communis Vita (CV), com a qual, no que tange aos religiosos, fez dois acréscimos ao cân. 694 do Código latino (CIC). O documento passou a vigorar desde o dia 10 de abril próximo passado. Com tais acréscimos, se procurou dar uma resposta adequada e eficaz para o problema da ausência ilegítima da casa religiosa em uma situação muito específica explicitada pela própria normativa.

É importante sublinhar, desde o início, que a legislação que rege demissão $a b$ homine facultativa (cân. 696, § 1), prevista para algumas situações, dentre as quais a ausência ilegítima da casa religiosa, permaneceu inalterada. Todavia, o Romano Pontífice reconheceu que nem sempre é possível localizar o religioso ausente e dar certeza jurídica à situação de fato. Justamente por isso, optou por considerar a ausência ilegítima da casa religiosa como causa de demissão ipso facto, caso perdure por doze meses contínuos e não seja realmente possível encontrar o religioso. Sendo assim, a partir da entrada em vigor do motu proprio $C V$, a ausência ilegítima da casa religiosa poderá gerar a 
demissão do religioso por meio de dois procedimentos distintos, dependendo da situação na qual se encontre. Se a ausência perdurar por doze meses contínuos e realmente não for possível a sua localização, a demissão se dará em conformidade com o cân. $694, \S 1,3^{\circ}$, seguindose o procedimento previsto pelo cân. $694, \S \S 2$ e 3, cuja finalidade é fazer com que o fato possa constar juridicamente. Em qualquer outra situação de ausência ilegítima da casa religiosa, prolongada por ao menos um semestre, continuará valendo o quanto estabelecido pelo cân. 696, § 1, respeitando-se o quanto estabelecem os cânn. 697-700.

Este artigo pretende retomar, de modo global e sintético, o tema da demissão dos religiosos ${ }^{2}$, mas sem se ocupar das três formas de demissão previstas pelo CIC atual e das diversas fattispecies contempladas pela normativa. $\mathrm{O}$ foco se voltará apenas para a questão da ausência ilegítima da casa religiosa como causa de demissão do instituto, tendo presente os aspectos substanciais e processuais da normativa em vigor. É necessário discernir bem a real situação do religioso ausente pois, de agora em diante, a ausência ilegítima da casa religiosa poderá gerar a demissão ab homine facultativa ou ipso facto, conforme o caso, sendo a segunda forma a maior novidade aportada à legislação pelo motu proprio $C V$.

Devido à extensão do argumento, o artigo está dividido em duas partes: na primeira, se fará um apanhado acerca da normativa que rege a demissão $a b$ homine facultativa por ausência ilegítima da casa religiosa prolongada por seis meses. Na segunda, à luz do motu proprio $C V$, se analisará a demissão ipso facto por ausência ilegítima da casa religiosa prolongada por doze meses sem que seja possível localizar o religioso ausente, indicando-se, também, os efeitos jurídicos que decorrem de qualquer forma de demissão legítima.

2 Como a normativa não faz distinção de sexo, toda a vez que no texto for utilizada a palavra "religioso" e/ou a palavra "superior", no singular ou no plural, valerá igualmente para os institutos masculinos e femininos, abrangendo "eles" e "elas", sem qualquer distinção, a não ser que pela natureza das coisas se restrinja o significado ao masculino, como, por exemplo, na menção a institutos clericais. 


\section{A demissão ab homine facultativa por ausência ilegítima da casa religiosa prolongada por seis meses (cân. 696, § 1).}

O motu proprio $C V$ não realizou qualquer alteração na normativa que rege a demissão $a b$ homine facultativa e, portanto, é a ela que se pode recorrer no caso de ausência ilegítima da casa religiosa prolongada por ao menos seis meses, a não ser que se verifique a situação tipificada pelo cân. $694, \S 1,3^{\circ}$. Sendo assim, convém recordar o que a legislação em vigor estabelece para que tal demissão se realize em conformidade com o direito e não seja dada qualquer margem para uma eventual impugnação, questionando-se sua legitimidade e/ou oportunidade.

\subsection{Noção e notas essenciais}

A demissão $a b$ homine facultativa ${ }^{3}$ é a expulsão do religioso feita pelo superior competente, mediante processo, observando-se rigorosamente o procedimento previsto pelo direito. Todavia, nessa forma de demissão, o direito não obriga o superior a agir, mas lhe dá a faculdade de realizá-la se houver uma conduta do religioso que a justifique, desde que tenha as seguintes notas essenciais: graves, externae, imputabiles et iuridice comprobatae. Tais notas devem se fazer presentes de modo cumulativo e simultâneo, pois, do contrário, não será possível iniciar o processo de demissão ${ }^{4}$.

3 A demissão $a b$ homine facultativa recebeu esta qualificação não porque o Superior pode a ela recorrer quando tiver vontade. Não se trata de modo algum de abrir as portas para a arbitrariedade de quem tem autoridade. O cân. 696 não contém uma declaração de força, mas quer oferecer um espaço quase processual ao qual se possa recorrer quando se verificarem as transgressões previstas pela norma. A facultatividade deve ser entendida como um juízo sobre a oportunidade ou não de se utilizar esta via para que seja mantida a disciplina religiosa, o restabelecimento da justiça e o serviço da caridade no instituto. Cf. DE PAOLIS, Velasio. La vita consacrata nella Chiesa. Venezia: Marcianum Press, 2015 (2 ${ }^{\mathrm{a}}$ Ed.), p. 583.

4 Andrés apresenta as hipóteses mínimas nas quais não se verificam todas as notas de modo cumulativo e simultâneo, impedindo, assim, o processo: "1) con una causa grave ma interna; 2) con una causa esterna ma lieve; 3) con una causa grave e esterna, ma non imputabile; 4) con una causa imputabile ma lieve e/o inter- 
A primeira nota indicada pelo cânon é a da gravidade. O CIC atual não define o que se entende por "grave". Uma ação poderá ser grave quando se refere a uma matéria em si mesma grave ou, então, a circunstâncias que poderão tornar grave uma matéria leve, sem que necessariamente se esteja diante de um delito.

A segunda nota se refere à exterioridade, o que não equivale a público ou notório, embora não raramente o que é exterior acabe por se tornar público. Uma violação é interna quando fica na esfera do pensamento ou do desejo, não tendo, portanto, maior relevância jurídica. Uma violação é externa quando, ao contrário, se manifesta, atinge o mundo exterior, podendo ser contestada e medida, sendo passível de uma avaliação jurídica em sua objetividade. Portanto, a demissão não poderá se basear em fatos que se limitam ao foro interno, sem qualquer projeção exterior, uma vez que não são demonstráveis.

A terceira nota é a da imputabilidade. Não é suficiente a existência de uma violação grave e externa. A causa da demissão deve ser fruto de um ato humano e, portanto, atribuível a um sujeito. Uma vez que a ele pertence, cabe-lhe responder moral e juridicamente pelo feito. Se, porventura, o religioso faltar com as suas obrigações devido a algum tipo de problema que possa afetar seriamente o seu discernimento e/ou liberdade, tornando-o inimputável, evidentemente que não poderá ser demitido. A inimputabilidade normalmente é demonstrada por meio de uma perícia médica.

A última nota se refere à prova jurídica. Nem todos os fatos externos, graves e imputáveis podem ser juridicamente provados. As provas jurídicas são obtidas através da confissão do acusado, de documentos diversos, de testemunhos, etc. Particular importância adquire aqui as admoestações ou advertências previstas pelo cân. $697,2^{\circ}$, pois constituem o meio necessário para demonstrar a incorrigibilidade do religioso. As provas devem ser sólidas e claras, não sendo suficientes meros indícios ou presunções de culpabilidade. Na demissão $a b$

na; 5) e con una causa non giuridicamente comprovata, sebbene sia esterna, grave ed imputabile, il superiore maggiore non può procedere ad iniziare il processo di dimissione, né a fortiori, il Moderatore supremo o il Vescovo diocesano possono giudicarla". ANDRÉS, Domingo. Le forme di vita consacrata. Commentario teologico - juridico al Codice di Diritto Canonico. Roma: Ediurcla, 2014 ( $7^{\mathrm{a}}$ Ed.), p. 673. 
homine facultativa, a finalidade do processo é justamente comprovar juridicamente os fatos, a sua gravidade, a imputabilidade do religioso e a sua incorrigibilidade. Isso vale para qualquer uma das causas indicadas pelo cân. 696, incluindo-se a da ausência ilegítima da casa religiosa prolongada por seis meses.

\subsection{A ausência ilegítima da casa religiosa}

O cân. $665, \S 1$ trata da ausência do religioso da casa religiosa, estabelecendo as condições que devem ser observadas pelos superiores para conceder a licença de ausência ${ }^{5}$. Se o religioso se ausentar ilegitimamente da casa religiosa com o intuito de se subtrair ao poder dos superiores, deverá ser por eles procurado com solicitude e ajudado para que retorne e persevere em sua vocação ${ }^{6}$.

Faz-se necessário, então, clarificar quando a ausência da casa religiosa é considerada ilegítima. Segundo Andrés, a ilegitimidade poderá nascer de fontes diversas, dentre as quais destaca: a ausência em absoluto de qualquer licença; a superação do tempo permitido e o não retorno sem qualquer justificativa ou explicação; a concessão da licença sem o consentimento do conselho ou contra a vontade do conselho; a concessão da ausência sem a existência de uma causa justa; a concessão da licença por um período superior a um ano sem que tenha sido por motivo de enfermidade, estudo ou apostolado em nome do instituto religioso; a concessão da licença por parte do superior local, mesmo se com o consentimento do conselho local; a concessão feita de modo legítimo, mas com a intenção, por parte do religioso, de se

5 Para um estudo mais aprofundado das condições necessárias para se conceder a licença prevista pelo cân. 665, § 1, ver: BAHILLO RUIZ, Teodoro Ángel. Los religiosos ausentes de la casa religiosa según el canon 665. Roma: Pontificia Università Lateranense, 1994, p. 97-150.

6 Andrés adverte que o superior é obrigado a procurar o religioso com solicitude, colocando em prática todos os meios humanos racionais e possíveis que favoreçam o seu retorno à casa religiosa e a perseverança em sua vocação. O superior poderá se valer de iniciativas flexíveis como, por exemplo, transferência para outro local, mudança de atividades, certas facilitações, desde que sejam possíveis e lícitas, no respeito ao direito universal e próprio. Cf. ANDRÉS, Domingo. Le forme di vita consacrata. Commentario teologico - juridico al Codice di Diritto Canonico. Roma: Ediurcla, 2014 (7ª Ed.), p. 468. 
subtrair ao poder dos seus superiores; outras semelhanças nas quais poderá faltar algum ou vários elementos de legitimidade ${ }^{7}$.

Embora a ilegitimidade da ausência possa ter várias fontes, na prática poderá derivar quer do religioso que a pede, quer do superior que a concede. O cân. 665, § 2, ao qual se refere o Papa Francisco no motu proprio $C V$, só se ocupa da primeira fonte. Sendo assim, o fato de uma ausência ser ilegítima não faz com que isso seja suficiente para que se proceda com a demissão. O legislador exige, ainda, a presença de uma intenção ou animus $^{8}$ de se subtrair ao poder dos superiores por parte do religioso. Se a ausência é ilegítima por causa de um erro dos superiores e sem que o religioso tenha consciência disso, evidentemente lhe falta o animus e não caberia demissão alguma. Se o religioso se ausentar da casa religiosa com o animus requerido pelo cânon, deve, primeiramente, ser procurado e ajudado a retornar. Somente se tal esforço for inútil e a ausência perdurar por seis meses ou mais é que se poderá proceder com a demissão do instituto?.

7 Ibidem. p. 467.

8 Este animus pode ser demonstrado pelas palavras, mas, sobretudo, pelas ações. Seria o caso do ausente que, após ter sido procurado e chamado, acaba não retornando, embora prometa que o fará, pois, na verdade, quer se subtrair ao poder dos superiores; ou, então, do ausente que desobedece, não retornando de fato, embora até diga que não tem a intenção de desobedecer. Se a ausência é ilegítima por causa de um erro dos superiores e sem que o religioso tenha consciência disso, evidentemente falta-lhe o animus de se subtrair ao poder dos superiores e, portanto, não cabe aqui demissão alguma.

9 Andrés observa que embora a demissão possa ser uma punição justa a ser imposta em certos casos, é sempre facultativa, tendo o superior a possibilidade de recorrer a outras punições fixadas pelo direito próprio, como por exemplo:"1) l'esclusione degli atti legittimi; 2) la privazione dei mestieri che aveva; 3) l'inabilitazione per i mestieri successivi; 4) la privazione perpetua o temporanea della voce attiva e/o passiva; 5) sospensione, se fosse ordinato in sacris, riservata al proprio moderatore supremo; 6) altre penitenze e rimedi penali salutari equivalenti, secondo le circostanze e in ogni caso imposte dentro lo spirito del non rigore del nuovo diritto penale della Chiesa, che tende piuttosto al recupero dell'interessato piuttosto che alla riparazione obiettiva di alcuni danni inferti al bene comune, a volte duraturi". ANDRÉS, Domingo. Il diritto dei religiosi. Roma: Ediurcla, 1996, p. 436-437. 


\subsection{Procedimento}

Na demissão $a b$ homine facultativa prevista, também, para o caso de ausência ilegítima da casa religiosa por um período de ao menos seis meses, com o intuito de se subtrair ao poder dos superiores, o processo se desenvolve em duas etapas (instrução e definição), cujo conteúdo aparece explicitado nos cânn. 697-700.

\subsubsection{Instrução}

A primeira fase cabe ao Superior maior ${ }^{10}$, a quem compete avaliar se deve ou não iniciar o processo de demissão. Em tal avaliação, ele precisa ouvir o seu conselho (cân. 697). Caso não o faça, sua ação será inválida, embora não esteja obrigado a seguir o voto do seu conselho, uma vez que o legislador deixa claro que se trata de voto consultivo ${ }^{11}$.

O juízo do Superior maior a respeito da necessidade, ou não, de se iniciar o processo de demissão, após ter ouvido o seu conselho, deve decorrer da existência de causas graves, externas, imputáveis e com a possibilidade de demonstrá-las juridicamente (cân. 696, § 1). Além disso, é preciso que conste, desde o primeiro momento, a aparente incorrigibilidade do religioso.

Ao se optar pelo processo de demissão, para o qual deverá ser nomeado um notário, o Superior maior precisará seguir os três passos

10 Conforme o cân. 620, Superiores maiores são os que governam todo o instituto, uma sua província, uma parte a ela equiparada ou uma casa autônoma, bem como seus vigários. A estes acrescentam-se o Abade Primaz e o Superior de congregação monástica que, todavia, não têm todo o poder que o direito universal confere aos Superiores maiores. Sendo assim, são Superiores maiores: o Moderador supremo, o Superior provincial e quase-provincial, o preposto ou Abade e todos os respectivos vigários. Na instrução da causa o Superior maior seria aquele que governa uma parte do instituto, caso seja dividido em partes, e que no direito recebe vários nomes, como, por exemplo, província.

11 O conselho de um superior não é uma mera formalidade, pelo contrário, pois ocupa um papel fundamental descrito pelo cân. 127. Na documentação relativa ao processo de demissão, é necessário que conste por escrito que, de fato, tal conselho foi ouvido antes do início do processo. 
fixados pelo legislador para a instrução do processo, de modo que sua ação seja legítima.

O primeiro passo consiste em reunir e completar as provas (cân. $697,1^{\circ}$ ) relativas ao motivo formal pelo qual se pretende demitir o religioso. No caso, se deve demonstrar que se está diante de uma ausência ilegítima prolongada por seis meses ou mais com o intuito de se subtrair ao poder dos superiores ${ }^{12}$. É necessário se valer de provas que atestem as notas exigidas por lei para se proceder com a demissão. Caso julgue que as provas não são suficientes, deverá completá-las antes de dar sequência ao processo.

Depois disso, poderá dar o segundo passo que consiste em advertir ou admoestar o religioso, por escrito ou diante de duas testemunhas, com a explícita ameaça de subsequente demissão, caso não se emende, indicando claramente a causa da demissão e dando-lhe plena faculdade de se defender. Se a advertência for inútil, deverá realizar uma segunda advertência, interpondo o espaço de pelo menos quinze dias entre uma e outra (cân. 697, $\left.2^{\circ}\right)^{13}$.

A admoestação canônica deve conter explicitamente a ameaça da demissão, caso o religioso não mude a sua conduta no tempo estabelecido, indicando-se claramente o que ele deve fazer ou não para evitá-la $^{14}$. É necessário explicitar a causa da possível demissão ${ }^{15}$ e o

12 Normalmente as provas são constituídas por testemunhos e documentos, além dos indícios e presunções. Para um estudo dos diversos tipos de prova, ver: ARROBA CONDE, Manuel J. Diritto processuale canonico. Roma: Ediurcla, 2012 (6 $6^{\mathrm{a}}$ Ed.), p. 408-502.

13 Embora seja verdade que as admoestações ou advertências são produzidas após o superior ter tomado a decisão de realizar o processo de demissão, elas estão ordenadas à correção daquele que as recebe. Não é correto considerá-las exclusivamente como um instrumento de demissão.

14 Sem a indicação explícita de que será demitido caso não mude de conduta, a admoestação ou advertência teria apenas um caráter fraternal e não seria considerada suficiente para se proceder com a demissão. O religioso em sua defesa poderia posteriormente alegar que não lhe foi informado sobre a possível demissão caso não mudasse de conduta.

15 Além de explicitar que o religioso poderá ser demitido, é necessário lhe informar qual seria a causa concreta de sua demissão. Não basta um apanhado geral da vida do religioso e nem a menção a eventuais problemas que ele causou ou causa no instituto. Aqui exige-se muita clareza. É preciso ser concreto. No caso, devese comunicar que a ausência é ilegítima e que o religioso está se subtraindo ao 
direito que o religioso possui de se defender ${ }^{16}$. A lei requer que isso seja feito por escrito ou verbalmente diante de duas testemunhas. $\mathrm{Na}$ segunda hipótese, faz-se uma ata firmada pelo Superior maior, pelas testemunhas, pelo notário e pelo religioso ${ }^{17}$.

Antes do motu proprio $C V$, o cumprimento da exigência das advertências encontrava sérias dificuldades nos casos em que o religioso se ausentava ilegitimamente da casa religiosa para se subtrair ao poder dos superiores e não deixava qualquer rastro que permitisse ao Superior maior localizá-lo. Como solução para o problema, se previa que as admoestações fossem enviadas para o último domicílio conhecido do religioso ou, então, para a residência dos seus pais ou parentes mais próximos, pedindo a eles, por meio de uma carta, que entregassem o documento ao religioso. Havia, ainda, a possibilidade de se valer de um edictum a ser fixado na última residência do religioso antes do seu desaparecimento. Evidentemente que tal documento deveria conter os mesmíssimos elementos que formam o conteúdo da admoestação. Do contrário, caso o religioso fosse demitido, poderia recorrer da decisão, alegando justamente a ausência de uma advertência prévia e legítima. Com o motu proprio $C V$ a solução para o problema se tornou bem mais simples, como se verá na segunda parte deste artigo, pois esse procedimento foi eliminado, uma vez que o próprio legislador agora responde a tal situação com a demissão ipso facto.

A lei estabelece que após a primeira advertência é preciso esperar ao menos quinze dias para verificar se o religioso mudou ou não a

poder dos seus superiores ao optar por não retornar à vida comunitária. Tal conduta será a causa de sua demissão, caso não se emende, cabendo-lhe a decisão de retornar ou não à vida em comum.

16 A finalidade da admoestação ou advertência é a correção do religioso e, justamente por isso, é necessário indicar a causa de sua possível demissão. Deve-se dar ele a possibilidade de se defender, provando a inexistência da causa alegada ou, então, justificando o seu comportamento.

17 O cân. 1509 afirma que a notificação das citações, sentenças e demais atos judiciais deve ser feita por correio ou por outro modo, o mais seguro possível, observando-se as normas estabelecidas por lei particular. Caso seja feita pelo correio, convém que se use o AR em mãos próprias, pois, desta forma, se teria uma segurança maior. Pode ocorrer de o religioso se recusar a assinar o documento. Neste caso, combinando-se o cân. 56 (âmbito administrativo) com o cân. 1510 (âmbito judiciário) a lei o terá por devidamente notificado. 
sua conduta ${ }^{18}$. Transcorrido o prazo, caso a situação permaneça inalterada, é necessária uma segunda advertência, repetindo-se o mesmo conteúdo da primeira, partindo-se, porém, da constatação de que a primeira resultou inútil e do exame de uma eventual defesa do religioso ${ }^{19}$.

Como destacado, nas admoestações deve-se indicar que o religioso tem o direito de se defender, podendo fazer isso por escrito (o documento deve ser assinado por ele) ou verbalmente. Na segunda hipótese, a sua declaração deverá ser feita diante do Superior maior e do notário, redigindo-se uma ata que, no final, será assinada pelos três. Se o religioso renunciar ao direito de se defender ou deixar passar o tempo que lhe foi dado sem nada fazer, isso deverá constar em um documento assinado pelo religioso ou pelo Superior maior e notário, conforme o caso. O importante é que conste no processo que o religioso teve, de fato, a oportunidade de se defender, mas não o fez. Caso o religioso mude de ideia, após ter renunciado ao exercício do seu direito, a sua defesa deverá ser admitida, com a condição de que tal manifestação seja feita dentro do prazo concedido para isso. É bom lembrar que o cân. 698 garante ao religioso o direito de se comunicar com o Moderador supremo, apresentando-lhe diretamente as suas alegações ${ }^{20}$. Existe, ainda, a possibilidade de o religioso recorrer diretamen-

18 Na legislação anterior, o superior deveria esperar ao menos três dias entre a primeira e segunda advertência (cân. 660). Lobina observa que na época a práxis da Congregação dos Religiosos havia alargado o prazo, estabelecendo um tempo mínimo de 15 dias e máximo de 3 meses. Com a promulgação do CIC atual, se diz apenas que o tempo mínimo será de 15 dias, podendo o Superior maior estender o prazo, segundo o seu prudente juízo. Cf. LOBINA, G. La separazione dei religiosi dall'Istituto. In: Apollinaris 61 (1983) p. 134-135.

19 Eventuais colóquios entre o Superior maior e o religioso por meio dos quais se tentou fazer com que o segundo se corrigisse, mesmo não se tratando de conversas formais, ordenadas diretamente ao processo de demissão, poderão ser úteis (quando documentados) para demonstrar que houve esforços por parte do Superior maior para recuperar o religioso. Muitas vezes, em tais conversas informais, o religioso explicita os motivos que tem para agir desta ou daquela maneira, embora possa ter optado por não se defender após o início do processo de demissão.

20 Poderá ocorrer que o acusado faça essa opção. Neste caso, o procedimento por parte do Superior maior imediato não seria interrompido, pois não se trata de um recurso contra o processo. Caberia a ele, antes de prosseguir com as admoestações e juízo a respeito da incorrigibilidade do religioso, tomar ciência do que foi 
te à Santa Sé em qualquer fase do processo. Caso isso ocorra, não se suspende o processo e a ação das autoridades inferiores.

Apenas após ter seguido os procedimentos anteriores é que se poderá dar o terceiro e último passo. Trata-se aqui da fase final da instrução. Depois de passados inutilmente quinze dias após a segunda e última advertência, o Superior maior com o seu conselho deverá analisar se consta a incorrigibilidade do religioso e se são insuficientes as suas alegações, caso as tenha apresentado.

Logo no início se afirmou que para se iniciar o processo de demissão tal conselho deveria ser ouvido. Agora, não se trata apenas de ouvir o conselho, mas, sim, de decidir com o conselho. Segundo Calabrese, este "decidir com o conselho" significa que a atuação será colegial $^{21}$. De Paolis, por sua vez, sustenta que tal intervenção não seria de natureza colegial ${ }^{22}$. A diferença não é irrelevante, pois, como bem observa Andrés, uma coisa é uma atuação colegial e outra coisa é uma atuação deliberativa. Na primeira, o conselho se torna um colégio, integrado pelo Superior maior que atua como um primus inter pares, cujo voto vale tanto quanto o dos demais membros do colégio. Tal colégio deve funcionar a teor do cân. $127, \S 1$, pois sua ação é colegial na substância e no modo de proceder: deve ser convocado; acolhe o voto da maioria absoluta dos presentes, salvo determinação contrário do direito próprio; a sua decisão ou o resultado é atribuível ao colégio e o Superior maior deve executar o quanto decidido. Na segunda, o conselho não perde a própria natureza consultiva em função do Superior. $\mathrm{O}$ Superior maior permanece fora ou acima do próprio conselho porque não pode ser conselheiro de si mesmo. Poderá funcionar conforme o cân. $127, \S 1$, mas como grupo de pessoas e não como colégio, ou a teor do cân. $127, \S 2$, como pessoas singulares, em conformidade com

apresentado ao Moderador supremo. Como alternativa, poderia encaminhar o quanto colhido na instrução do processo ao Moderador supremo, destacando que o religioso não quis se defender perante ele e seu conselho. Cf. GAMBARI, Elio. I religiosi nel codice. Commento ai singoli canoni. Milano: Ancora, 1986, p. 367-368.

21 CALABRESE, Antonio. Istituti di Vita Consacrata e Società di Vita Apostolica. Città del Vaticano: Libreria Editrice Vaticana, 2011 ( $3^{\mathrm{a}}$ Ed.), p. 322.

22 Cf. DE PAOLIS, Velasio. La vita consacrata nella Chiesa. Venezia: Marcianum Press, 2015 (2a Ed.), p. 583. 
o direito próprio. Uma vez dado o voto deliberativo, o ato sucessivo é exclusivo e pessoal do Superior maior, uma vez que a intervenção do conselho é uma condição posta pela lei para que ele possa decidir. O Superior maior poderá agir ou não, mas se opta por agir, deverá seguir o que foi determinado pelo voto deliberativo do seu conselho ${ }^{23}$.

Se o cân. 699, ao se referir ao Moderador supremo com o seu conselho, afirma claramente que a decisão será de natureza colegial, o cânon em análise simplesmente afirma que o Superior maior agirá com o seu conselho, sem qualquer menção a uma intervenção de natureza colegial. Tendo presente a história da formação do cânon, nem no Schema de 1977 e nem naquele de 1980 indica-se a necessidade de uma intervenção colegial na fase de instrução do processo. No Schema de 1977 o procedimento colegial não aparece em momento algum ${ }^{24} \mathrm{e}$ naquele de 1980 o grupo de estudos optou por um procedimento colegial apenas no momento de decisão final e não na instrução do processo $^{25}$. O cânon elaborado no Schema de 1980 permaneceu praticamente inalterado até a promulgação do CIC atual e, por conseguinte, é possível sustentar que, de fato, não se exige no encerramento da instrução do processo qualquer decisão de natureza colegial. Todavia, convém recordar que o Superior maior agirá invalidamente se, ao avaliar a incorrigibilidade do religioso $^{26}$ e a sua defesa, prescindir do seu conselho ou agir contra a sua decisão.

23 Cf. ANDRÉS, D. J. Il diritto dei religiosi. Roma: Ediurcla, 1996, p. 149.

24 Cf. PONTIFICIA COMMISSIO CODICI IURIS CANONICI RECOGNOSCENDO. Schema Canonum De Institutis Vitae Consecratae per professionem consiliorum evangelicorum (reservatum). Città del Vaticano: Typis Polyglottis Vaticanis, 1977.

25 Cf. Communicationes 13 (1981) p. 349-350.

26 Avaliar a incorrigibilidade do religioso pode apresentar algumas dificuldades práticas. Não raramente o religioso promete se emendar, muda a sua atitude, mas em pouco tempo tudo volta a ser como antes. Neste caso, Egaña oferece a seguinte indicação: "Quando il religioso, pur promettendo di emendarsi, ricade, occorre analizzare, sempre in sede di consiglio, due aspetti: a) l'aspetto personale: si deve cercare di verificare, con certezza morale, se tra le mancanze ci sia un nesso morale tale che manifesti una oggettiva mancanza di volontà di emendarsi, o si tratti piuttosto di una debolezza che dimostra però palesemente l'incapacità del religioso di vivere secondo le esigenze della vita consacrata; b) l'aspetto istituzionale: occorre anche analizzare se, pur trattandosi di debolezze, la loro grave, 
Por fim, uma vez constatada a incorrigibilidade do religioso após as duas advertências e a insuficiência do quanto alegado por ele em sua defesa, o Superior maior deverá transmitir ao Moderador supremo ou ao Bispo diocesano (quando se tratar de um membro de um mosteiro sui iuris) todos os autos, assinados pelo próprio Superior maior e pelo Notário, juntamente com as respostas do acusado e por ele assinadas (cân. 697, $\left.3^{\circ}\right)^{27}$.

\subsubsection{Definição}

A segunda fase do processo é de responsabilidade do Moderador supremo com o seu conselho, tal como estabelece o cân. 699. Também nela é necessário seguir rigorosamente os passos fixados pelo legislador.

Primeiramente, o Moderador supremo, com seu conselho que, para a validade, deverá constar de ao menos quatro membros, proce-

imputabile e giuridicamente comprovata ripetizione, costituisca un danno per l'istituto, a causa dello scandalo che provoca. Essendo la dimissione di cui il c. 696 una sanzione di tipo espiatorio "non obbligatoria", ma facoltativa, perché i membri giudicati oggettivamente nocivi all'istituto possano essere separati dallo stesso, e riparato il disordine o danno causato alla vita religiosa, dalla infrazione, i superiori, nel valutare le mancanze oggettive ripetute (per cattiva volontà o per debolezza) devono tenere conto del danno che tali soggetti o mancanze provocano nell'istituto, e non giudicare soltanto con un criterio punitivo dell'infrazione stessa". Cf. EGAÑA, F. J. Gli IVC e le SVA. Questione canonica: come valutare $l^{\prime}$ incorreggibilità in ordine alla dimissione di cui al c. $697,3^{\circ}$, quando il religioso, pur promettendo di emendarsi, tuttavia ricade, entro uno spazio di tempo più o meno lungo, negli stessi delitti o in altri simili? In: Vita Consacrata 28 (1992) p. 484-485.

27 A documentação transmitida ao Moderador supremo deve conter as duas advertências, a defesa escrita do religioso (se houver) e o juízo acerca de sua incorrigibilidade feito pelo Superior maior e o seu conselho. Cada página do dossier deverá trazer a assinatura do Superior maior e do notário. A práxis consolidada exige, ainda, o comprovante de que o religioso recebeu, de fato, as duas admoestações. Isso se faz colhendo as assinaturas dele ou demonstrando que ele se recusou a assinar os documentos. É frequente que os atos do processo sejam acompanhados de alguns documentos (anexos) que ilustram todo o caminho percorrido até se chegar à decisão de demitir o religioso. Em tais anexos não é necessário observar todas as formalidades exigidas. 
derá colegialmente ${ }^{28}$ para avaliar com cuidado as provas, argumentos e alegações e, se assim for decidido por voto secreto, fará o decreto de demissão, expondo, também para a validade, ao menos sumariamente, os motivos de direito e de fato (cân. $699, \S 1$ ). Nos mosteiros sui iuris a decisão é de competência do Bispo diocesano, a quem o Superior maior deverá submeter os autos aprovados por seu conselho (cân. 699, $\S 2)^{29}$.

A composição do colégio, no modo indicado pelo legislador, afeta, como observado, a validade do decreto de demissão. Por conseguinte, se o conselho não tiver ao menos quatro membros ou, então, se tiver quatro membros, mas algum deles estiver impedido ou ausente, de modo legítimo ou ilegítimo, o Moderador supremo, para observar o número mínimo fixado pelo direito universal, se verá obrigado a suprir tal ausência com a convocação de outro religioso idôneo ${ }^{30}$.

28 Aqui não há uma distinção entre Superior e Conselho, razão pela qual não se aplica a interpretação autêntica ao cân. 127 feita pelo então Pontifício Conselho para a Interpretação dos Textos Legislativos (AAS 77 [1985] 771). O procedimento adotado será de natureza colegial, razão pela qual vale o quanto previsto pelo cân. 119 .

29 No caso dos mosteiros sui iuris a decisão cabe ao Bispo diocesano porque neles, além do próprio Superior, não há outro Superior maior e nem são associados a outro instituto religioso com um vínculo de subordinação determinado pelas Constituições. Tais mosteiros não podem ser abandonados a si mesmos. Para garantir a reta disciplina, são confiados à particular vigilância do Bispo do lugar em que a sede se encontra o qual, por sua vez, deverá atuar em conformidade com o direito universal e próprio. Cf. CHIAPPETTA, Luigi. Il Codice di Diritto Canonico. Commento giuridico-pastorale. Roma: Edizioni Dehoniane. Vol. 1, 1996, p. 753 .

30 Elio Gambari destaca que caso o conselho seja composto por um número superior a quatro conselheiros, não se exige a presença de todos os membros, desde que se observe o número mínimo fixado por lei. Todavia, o direito próprio poderá exigir que, no caso, para a validade da decisão, todos os conselheiros se façam presentes. Cf. GAMBARI, E. I religiosi nel codice. Commento ai singoli canoni. Milano: Ancora, 1986, p. 369. Jean Beyer acrescenta, por sua vez, que nada impediria que o direito próprio optasse por exigir um colégio mais competente para decidir sobre a demissão. Cf. BEYER, Jean. Le Droit de la Vie Consacrée. Instituts et Sociétés. Paris: Editions Tardy, 1988, p. 198. 
Caberá ao Moderador supremo e aos conselheiros analisar cuidadosamente a documentação recebida, desde um ponto de vista processual e substancial.

Em relação à substância, é fundamental que se avalie as provas sobre as quais se baseia o juízo do Superior maior para dar início ao processo de demissão e para levá-lo adiante. É preciso verificar se os fatos atribuídos ao religioso são graves, externos, imputáveis e juridicamente demonstrados, tendo por referência as provas recolhidas no processo (documentos, testemunhos, etc.). Além disso, é necessário avaliar se os argumentos utilizados pelo religioso para se defender são fundados e suficientes e se consta a sua incorrigibilidade, não obstante as possibilidades e meios que lhe foram oferecidos para que se emendasse.

Em relação ao processo, é necessário verificar se todas as formalidades foram cumpridas, ou seja, se houve a consulta prévia do Superior maior ao seu conselho antes de iniciar o processo e na conclusão da instrução; se as admoestações feitas indicam a(s) causa(s) da demissão e a conduta que o religioso deveria adotar para evitá-la; se os prazos entre as duas advertências foi observado; se o religioso pôde apresentar a sua defesa e, caso tenha renunciado a realizá-la, se isso consta no processo. Se tudo estiver em ordem, se vai adiante. Do contrário, poderá ser solicitado um complemento de instrução ou a correção de eventuais falhas.

Uma vez concluído o estudo dos autos por parte de cada membro, caberá ao colégio, presidido pelo Moderador supremo, tomar a decisão final, procedendo em conformidade com o quanto estabelecido pelo cân. 119, o qual prevê a necessidade de uma convocação e de uma ação colegial secreta. Aqui o Moderador supremo participa do conselho como um primus inter pares e não como superior do conselho. O seu papel consistirá em presidir a sessão, uma vez que o seu voto valerá tanto quanto o dos demais membros. Valerá o que decidir a maioria e, no caso de empate, o presidente do colégio poderá dirimir a paridade com o seu voto (cân. $\left.119,2^{o}\right)^{31}$. Embora a decisão caiba ao

31 Em relação a ação do colégio, Jean Beyer assim se manifesta: "Bisogna che essa sia veramente collegiale, presa in seduta, alla presenza di tutti i membri; questi ultimi devono aver assistito a tutte riunioni, potervi manifestare oralmente il loro 
colégio, a emissão do decreto de demissão cabe ao Moderador supremo, pois se trata de um ato de sua competência, mesmo se tiver sido voto vencido no colégio.

O decreto de demissão, para que seja válido, deverá ser emanado por escrito e conter, ao menos sumariamente, os motivos de direito e de fato da decisão tomada (cân. $699, \S 1)^{32}$.

Em relação à exposição dos motivos in iure, é fundamental a enumeração e descrição dos fatos puníveis pelo direito universal e/ou próprio e imputáveis ao religioso. $\mathrm{Na}$ exposição dos motivos in facto, Calabrese recorda acerca da importância de uma certa animadversio, isto é, de um raciocínio com o qual, avaliando-se as provas e a defesa, se deduza, com a devida certeza moral, que os fatos são graves, externos e imputáveis ao religioso e que o mesmo religioso não se emendou, não obstante as duas advertências, e que, tendo sido respeitado o quanto estabelecido pela norma no que tange ao procedimento, ele deve ser demitido $^{33}$. Não se exige uma longa exposição, mas que o texto seja concreto e pontual. Além da indicação dos motivos de direito e de fato, o cân. 700 exige, também, que o decreto, para ser válido, mencione o direito que o demitido tem de recorrer à autoridade competente dentro do prazo de dez dias após receber a notificação do decreto.

parere ed esprimere alla fine, con voto segreto, la loro decisione, per mezzo di un sì o un no chiaramente enunciato. Ciò non si può fare per telefono e con altri mezzi di comunicazione; la presenza di tutti i membri è necessaria a questo agire collegiale. Cf. BEYER, Jean. "La dimissione nella vita consacrata". In: Vita Consacrata 28 (1992) p. 168.

32 A exposição por escrito dos motivos da decisão é um elemento próprio de qualquer decreto decisório (cân. 51). Esta exigência se justifica tendo por base uma dupla razão: $1^{\text {a }}$ Evitar possível ação arbitrária da autoridade e garantir a objetividade do decreto; $2^{\text {a }}$ Permitir que o destinatário do decreto tenha a possibilidade de conhecer as razões da decisão e de recorrer, caso não esteja de acordo com a decisão. Cf. GARCÍA MARTÍN, J. Le norme generali del Codex Iuris Canonici. Roma: Ediurcla, 1996, p. 218. Lobina recorda que esta exigência vale igualmente para os Dicastérios da Cúria Romana que também devem motivar brevemente in iure et in facto todos os decretos decisórios que emanarem. Cf. LOBINA, G. La separazione dei religiosi dall'Istituto. In: Apollinaris 61 (1983) p. 138.

33 Cf. CALABRESE, Antonio. Istituti di Vita Consacrata e Società di Vita Apostolica. Città del Vaticano: Libreria Editrice Vaticana, 2011 (3ª Ed.), p. 323. 
Particular atenção merece a exigência legal de uma confirmação prévia do decreto por parte da Santa Sé ou do Bispo diocesano, conforme o caso, antes de sua notificação ao interessado ${ }^{34}$. É preciso esclarecer qual é a natureza desta confirmação.

LLobell coloca a questão nos seguintes termos: a confirmação por parte da autoridade é um requisito intrínseco do decreto de demissão (para torná-lo perfeito) ou extrínseco, como se fosse uma condição suspensiva que adiaria a sua eficácia? Segundo ele, a resposta dada pela Pontificia Commissio Codici Iuris Canonici Authentice Interpretando $^{35}$ (bem como a ulterior ajuda por parte do cân. 500, § 4 do CCEO) não deixa qualquer margem de dúvida. O decreto de demissão do religioso atingiria a sua perfeição intrínseca antes mesmo de sua confirmação. Isso significa que, se o decreto for elaborado no respeito ao quanto estabelecido pelo direito, será de per si válido, embora não

34 Na elaboração do cânon a intenção do grupo de espertos era a de não impor a confirmação. Isso só ocorreu na última sessão plenária (1981) da Comissão para a preparação do CIC com a intenção de defender melhor os direitos dos religiosos, especialmente das mulheres que, frequentemente pobres e desprovidas de instrução, não teriam como se valer da via do recurso hierárquico ou do processo administrativo. Cf. BEYER, J. Risposte della Pontificia Commissione per l'autentica interpretazione del Codice: Il decreto di dimissione emesso dal moderatore supremo secondo il c. $700 \mathrm{del} \mathrm{CDC}$, deve essere notificato alla persona prima della conferma da parte della Santa Sede, o dopo tale conferma? In: Vita Consacrata 25 (1989) p. 67.

35 Na dúvida formulada se perguntava se o decreto de demissão dado pelo Moderador supremo, à norma do cân. 700 do CIC, deveria ser notificado ao demitido antes ou após a confirmação da Santa Sé: "D. Utrum decretum dimissionis iuxta can. 700 CIC a Moderatore supremo prolatum dimisso notificandum sit ante Sanctae Saedis confirmationem, aut pot eiusdem confirmationem. R. Negative ad primam partem; affirmative ad alteram". Além disso, se perguntava se a autoridade competente para receber o recurso, com efeito suspensivo, contra a demissão do religioso fosse a Congregação para os Religiosos e Institutos Seculares que teria confirmado o decreto ou o Supremo Tribunal da Assinatura Apostólica:"D. Utrum auctoritas competens ad recipiendum recursum in suspensivo contra sodalis dimissionem sit Congregatio pro Religiosis et Institutis Saecularibus, quae decretum confirmavit, aut Supremum Signaturae Apostolicae Tribunal. R. Affirmative ad primam partem; negative ad alteram". Cf. Pontificia Commissio Codici Iuris Canonici Authentice Interpretando. In: Acta Apostolici Sedis 78 (1986) p. 1323-1324. 
eficaz, na medida em que os seus efeitos só serão produzidos após o controle prévio da autoridade competente ${ }^{36}$.

Di Mattia, por sua vez, sustenta que não seria exato afirmar que o ato de demissão é plenamente válido (validitas), mas apenas privado de força ou eficácia (vis), estabelecendo-se entre eles uma nítida separação substancial. Nem mesmo seria correto afirmar que se trataria de um ato válido, mas na espera de uma confirmação. Para ele, a confirmação, uma vez constatada a presença de todos os requisitos legais, verifica a legitimidade e faz emergir a eficácia inserida no próprio ato $^{37}$.

Ao que tudo indica, a então Pontificia Commissio Codici Iuris Canonici Authentice Interpretando, ao esclarecer que a autoridade para conhecer o recurso mencionado pelo cân. 700 é a Congregação dos Religiosos e Institutos seculares (atual Congregação para os IVC e SVA), resolveu a questão a respeito da confirmação e as dúvidas levantadas pela doutrina. Na prática, se reafirmou que o autor do decreto de demissão é o Moderador supremo com o seu conselho e que a confirmação não é uma espécie de "recurso automático" e nem acrescenta qualquer coisa para a validade do decreto. Tal decreto é completo e perfeito desde o momento em que foi formulado pelo organismo competente. Como bem o recorda Gomez-Iglesias, a confirmação exi-

36 Cfr. LlOBELL, J. La conferma del decreto di dimissione del religioso a norma del can. 700. Note sull'ermeneutica degli istituti rivolti all'attuazione del diritto di difesa. In: Ius Ecclesiae 4 (1992) p. 240-241. A opinião segundo a qual o decreto, uma vez observado o quanto estabelecido pelo direito, é válido (perfeito em si mesmo), mas não eficaz, porque a notificação válida depende de uma confirmação prévia, a encontramos, também, em Andrés, Ghirlanda e Jean Beyer. Cf. ANDRÉS, Domingo. Le forme di vita consacrata. Commentario teologico juridico al Codice di Diritto Canonico. Roma: Ediurcla, 2014 (7 $7^{\mathrm{a}}$ Ed.), p. 670; GHIRLANDA, G. Il diritto nella Chiesa, mistero di comunione. Roma: San Paolo, 1993, p. 225; BEYER, J. Risposte della Pontificia Commissione per l'autentica interpretazione del Codice: Il decreto di dimissione emesso dal moderatore supremo secondo il c. 700 del CDC, deve essere notificato alla persona prima della conferma da parte della Santa Sede, o dopo tale conferma? In: Vita Consacrata 25 (1989) p. 69.

37 Cf. DI MATTIA, G. Separazione dei membri dall'Istituto e dalla Società di Vita Apostolica. Tipologia e procedura. In: Commentarium pro Religiosis et Missionariis 74 (1993) p. 45. 
gida pelo cânon não pode ser confundida com aquela de natureza constitutiva do ato jurídico, como seria o caso, por exemplo, da confirmação de uma eleição para um ofício eclesiástico (cân. 147). Tratase aqui de uma confirmação entendida como um ato de controle sucessivo de tutela e, justamente por isso, é que não muda o autor do ato, embora sujeito à vigilância da autoridade confirmante. Portanto, no caso do decreto de demissão, o controle sucessivo do Dicastério competente (para os institutos de direito pontifício) não faz com que o decreto a ele pertença ${ }^{38}$. Na mesma direção se move LLobell, pois sustenta que o decreto de demissão é obra exclusiva do Moderador supremo do instituto com o seu conselho (ou do Bispo, no caso dos mosteiros sui iuris), pois se a confirmação da autoridade comportasse uma coparticipação na decisão tomada pelo órgão decisório do instituto, teria fundamento a posição segundo a qual o único recurso possível seria junto à sectio altera do Supremo Tribunal da Assinatura Apostólica, o que foi excluído pela segunda resposta dada pela então Pontificia Commissio Codici Iuris Canonici Authentice Interpretando ${ }^{39}$. Ele reafirma que o controle da autoridade competente sobre o decreto seria apenas extrínseco, uma vez que o juízo sobre o mérito do decreto (e não sobre a existência de fumus boni iuris relativo ao mérito) só ocorrerá posteriormente, caso haja um eventual recurso junto a autoridade que confirmou o decreto, após a sua notificação ao interessado ${ }^{40}$.

Tendo esclarecido que a confirmação é necessária, não para a validade do decreto, mas para a sua eficácia, alcançada com a sua notificação e precedida por tal confirmação, resta saber qual é o tipo de controle que a autoridade confirmante realiza sobre o decreto. Segundo LLobell, tal autoridade deve examinar se o decreto possui todas as formalidades previstas pela lei e se, a partir dos autos recebidos,

38 Cf. GOMEZ-IGLESIAS, V. El decreto de expulsión del canon 700 y las garantías jurídicas del afectado. In: Ius Canonicum 27 (1987) p. 668. Cf. PONTIFICIA COMMISSIO CODICI IURIS CANONICI AUTHENTICE INTERPRETANDO. In: Acta Apostolicae Sedis 78 (1986) p. 1323-1324.

40 LLOBELL, J. La conferma del decreto di dimissione del religioso a norma del can. 700. Note sull'ermeneutica degli istituti rivolti all'attuazione del diritto di difesa. In: Ius Ecclesiae 4 (1992) 251. 
emerge um suficiente fumus boni iuris a respeito do mérito ${ }^{41}$, não cabendo a autoridade confirmante um juízo de mérito no sentido de poder utilizar as amplas faculdades que o cân. 1739 lhe concede na fase do recurso ${ }^{42}$. Para ele, a demissão do religioso será, também, uma obra da autoridade confirmante somente após o julgamento do recurso, dando-se execução ao decreto confirmado ${ }^{43}$.

Tendo sido confirmado o decreto de demissão por parte da competente autoridade, o religioso deverá ser notificado da decisão. Esta

41 O autor exemplifica o que deveria ser objeto de análise por parte da autoridade confirmante: "L'esistenza della giusta causa - prima facie- per la dimissione, a norma dei cann. 695, $\S 1$ e 696; l'inefficacia - secondo il parere del Moderatore e del suo consiglio - delle ammonizioni di cui al can. 697; il rispetto essenziale del diritto di difesa (cann. 695, § 2, 697 e 698); la presenza negli atti di prove idonee a produrre sull'organo decisorio la certezza morale sull'imputabilità dei fatti al dimesso (cann. 695, § 2 e 696); l'adempimento dei requisiti formali del decreto. L'autorità deve controllare, ad es., se vi siano la motivazione (cann. 51 e $699, \S 1$ ), la decisione collegiale (can. 699), l'indicazione del diritto di ricorrere con effetto sospensivo (can. 699), la data e le firme previste (can. 54, § 2, 124, § $1,127,699,1612, \S 4,1622,3^{\circ}$ e $\left.4^{\circ}\right)$ '. Cf. LLOBELL, J. La conferma del decreto di dimissione del religioso a norma del can. 700. Note sull'ermeneutica degli istituti rivolti all'attuazione del diritto di difesa. In: Ius Ecclesiae 4 (1992) p. 241-242.

42 Secondo Di Mattia, a afirmação de que a autoridade que confirma o decreto não pode entrar no mérito da demissão, mas, apenas, deve analisar a legitimidade do decreto, podendo entrar no mérito somente quanto houver o recurso, pois, do contrário, seria coautora do decreto e o recurso deveria ser dirigido à Assinatura Apostólica, o que não foi admitido pela Pontifícia Comissão para a autêntica Interpretação do CIC, trás consigo dois problemas, assim apresentados por ele: "Se è vero che il ricorso sarà interposto presso il Dicastero competente che ha confermato il decreto solo perché questo ne ha valutato la sua legittimità, senza entrare nel merito, limitandosi quindi ad un controllo estrinseco, a chi competerebbe giudicare un ricorso presentato dal dimesso, dichiarando che il decreto è illegittimo, senza questionare però la sua opportunità, una volta che il Dicastero competente già si sia pronunciato sulla sua legittimità? Se, invece, si ammette che il Dicastero entra anche nel merito, si ricade nella figura giuridica dello stesso giudice che conosce la stessa controversia due volte". DI MATTIA, G. Separazione dei membri dall'Istituto e dalla Società di Vita Apostolica. Tipologia e procedura. In: Commentarium pro Religiosis et Missionariis 74 (1993) p. 46.

43 Cf. LLOBELL, J. La conferma del decreto di dimissione del religioso a norma del can. 700. Note sull'ermeneutica degli istituti rivolti all'attuazione del diritto di difesa. In: Ius Ecclesiae 4 (1992) 242. 
notificação deve ocorrer nas formas prescritas pelo direito para casos semelhantes: entrega de uma cópia do decreto ao interessado na presença de duas testemunhas ou por meio dos serviços postais (convém que seja o $\mathrm{AR}$ em mãos próprias) ou por qualquer outro meio seguro. É preciso que conste nos autos que, de fato, houve a notificação ${ }^{44}$. $\mathrm{O}$ cân. 55 permite que quando uma gravíssima razão impedir a entrega do texto do decreto, o documento seja lido ao interessado diante de um notário ou de duas testemunhas, redigindo-se um ato que deve ser assinado por todos os presentes. O cân. 56 recorda que se tem por intimado o decreto, se aquele a quem se destina, devidamente convocado para receber ou ouvir o decreto, sem justa causa não comparecer ou se recusar a assinar. Segundo o cân. 700, é preciso informar ao religioso que dispõe do prazo de dez dias, após ter recebido a notificação do decreto $^{45}$, para apresentar recurso, se o desejar, tendo tal procedimento efeito suspensivo.

44 Gómez-Iglesias recorda que apesar do cân. 700 se referir à necessidade de uma notificação tendo em vista um possível recurso, pressupondo, portanto, uma decisão positiva, não quer dizer com isso que no caso de uma decisão favorável ao religioso por parte da autoridade interna do instituto, o religioso não deva ser notificado. Não seria correto, nesse caso, manter um silêncio sobre o resultado do processo, uma vez que o interessado tem o direito de saber que a decisão the foi favorável. Cf. GOMEZ-IGLESIAS, V. El decreto de expulsión del canon 700 y las garantías jurídicas del afectado. In: Ius Canonicum 27 (1987) p. 666. Gómez-Iglesias esclarece que na resposta dada pela Pontifícia Comissão para a Interpretação Autêntica do CIC eliminou-se a dúvida a respeito da necessidade ou não de se solicitar a revogação do decreto de demissão ao seu autor antes de se apresentar o recurso hierárquico, à norma do cân. 1734: "Antes de la respuesta se podría pensar que la segunda parte del canon 700 se refería a esa petición, supplicatio ou oppositio cuando habla del recurso que ha de interponerse en el plazo de diez días a la autoridad competente, plazo similar al señado en el can. 1734. Después de la respuesta está claro que la "autoridad competente" es el Dicasterio de Religiosos y que estamos ante el recurso jerárquico. Del iter redaccional y de la propia normativa sobre expulsión de religiosos no se puede inferir aquella exigencia; el procedimiento de emanación del decreto y su posterior confirmación, notificación y recurso están regulados por los cánones 695 y seguientes que contemplan suficientes intervenciones tanto de los Superiores del Instituto como del afectado - amonestaciones con advertencia de expulsión en caso de incorregibilidad, audiencia y defensa del interesado, valoración posterior de esta defensa, etc. - así como del Dicasterio de Religiosos y non hacen mención de este nuevo conocimiento del asunto por parte del Superior General y su Consejo”. 
À primeira vista, esta exigência do legislador poderia parecer supérflua, uma vez que o cân. $221, \S 1$ garante a todos os fiéis o exercício de um direito processual e o cân. 1737, § 1 estabelece que quem sustenta estar onerado por um decreto, poderá recorrer ao Superior hierárquico daquele que emanou o decreto por qualquer motivo justo. Mas, segundo Jean Beyer, esta decisão do legislador veio em benefício e ajuda para o demitido e inclusive seria desejável que a autoridade fornecesse ao religioso todas as informações necessárias para apresentar o seu recurso, caso assim o deseje $\mathrm{e}^{46}$.

Uma questão que suscitou discussões diz respeito a autoridade à qual o religioso demitido poderá apresentar o seu recurso. Alguns não estavam de acordo que o Dicastério que confirmou o decreto pudesse receber o recurso contra o decreto de demissão. Tal objeção tinha por fundamento razões mais de ordem psicológica que jurídica, como bem observou J. Beyer ${ }^{47}$. Andrés, por sua vez, sempre defendeu a compe-

GOMEZ-IGLESIAS, V. El decreto de expulsión del canon 700 y las garantías jurídicas del afectado. In: Ius Canonicum 27 (1987) p. 668-669.

46 J. Beyer destaca que a exigência contida no cân. 700 faz justiça e leva em consideração a falta de informação geral dos religiosos. Além disso, sugere: "De plus, il faudrait, pour être juste, signifier au religieux renvoyé comment il doit faire pour attester la date de la réception qui marque le début du temps à courir pour que le recours soit recevable. Ce temps vaut pour l'envoi du recours ; il ne conditionne pas l'arrivée et l'admission du recours auprès de l'autorité compétente". Cf. BEYER, J. Le Droit de la Vie Consacrée. Instituts et Sociétés. Paris: Editions Tardy, 1988, p. 199.

47 Afirma o autor: "Perché è anzitutto competente la Congregazione che ha approvato il decreto? La cosa è evidente. La conferma del decreto è obbligatoria perché il decreto, che ha validità e vigore per se stesso, sia correttamente notificato e applicato, cioè, posto in esecuzione. La conferma è per garantire una più sottomissione, e non impedisce il ricorso; di più, colui che ottiene la conferma non è il dimittendo, ma il superiore che l'ha chiesta a norma del diritto. In tale materia, dal punto di vista giuridico non c'era alcun motivo di dubbio. Ma dal punto di vista psicologico, diversi elementi possono spiegare l'opinione erronea. L'autorità che dà la conferma e che riceve il ricorso è la medesima, e ad essa vano trasmessi tutti gli atti; si suppone un completo esame e una piena cognizione della causa. Ma una stessa autorità che ha confermato il decreto, può poi revocarlo, dichiararlo ingiusto, esigere un nuovo esame della causa? In sé, la cosa è possibile, anche se a molti pare di dubbio valore una tale revisione da parte dell'autorità che ha negligentemente confermato il decreto, e potrà riesaminare la pratica con animo non benevolo; a meno che nel dicastero stesso esista un ufficio 
tência do atual Dicastério, tendo por base as seguintes razões: $1^{\mathrm{a}}$ ) porque a confirmação do decreto por parte da Congregação dos IVC e SVA se limitou a dar vim al decreto, liberando a sua notificação, sem se tornar com isso a autora do decreto; $2^{a}$ ) porque um ato do Superior ou Moderador supremo seria julgado em sede de recurso pela Assinatura Apostólica, saltando a imediata competência do Dicastério; $3^{\mathrm{a}}$ porque a Assinatura Apostólica não poderia entrar no mérito da cau$\mathrm{sa}^{48}$. Na verdade, a dúvida surgida, desde um ponto de vista jurídico, deriva de uma visão não muito clara a respeito da distinção entre confirmação e recurso e sobre a competência do Dicastério nessa questão.

Superadas as discussões, não há atualmente qualquer dúvida a respeito da autoridade competente para receber um eventual recurso do demitido. Será sempre a mesma que confirmou o decreto, isto é, a atual Congregação dos IVC e SVA para os institutos de direito pontifício e mosteiro sui iuris, dentro de dez dias após a notificação do decreto. Em relação aos institutos ou sociedades de direito diocesano, antes do recurso ao Dicastério, será necessário apresentar o recurso ao Bispo que confirmou o decreto, dentro do mesmo prazo ${ }^{49}$. Somente depois disso é que será possível apresentar o recurso junto à Congregação dos IVC e SVA, dentro de quinze dias, a norma do cân. 1737, § 2.

speciale per ricevere i ricorsi, o almeno il ricorso sia esaminato collegialmente; ma di quest'ultima sicurezza del diritto da esercitare nulla è detto né richiesto. Tale distinzione di procedura tuttavia, per ragione di giustizia è auspicabile, e forse dovrebbe essere stabilita nel documento legislativo". Cf. BEYER, J. Risposte della Pontificia Commissione per l'autentica interpretazione del Codice: L'autorità competente a ricevere il ricorso in sospensivo contro la dimissione di un membro, è la Congregazione per i Religiosi e gli istituti secolari, che ha confermato il decreto, o il Supremo Tribunale della Segnatura Apostolica?. In: Vita Consacrata 25 (1989) p. 70.

48 Cf. ANDRÉS, D. J. De recursu contra decretum dimissionis suscipiendo a SCRIS (c.700). In: Commentarium pro Religiosis et Missionariis 67 (1986) 291292.

49 No Schema del 1980 estudou-se a possibilidade de se permitir aos institutos de direito diocesano a apresentação do recurso diretamente à Santa Sé, dentro do prazo de dez dias, sem necessidade de se recorrer preliminarmente ao Bispo. $\mathrm{Na}$ redação posterior, optou-se por manter a competência de receber o recurso à autoridade que confirmou o decreto. Cfr. Communicationes 13 (1981) p. 350. 
Caso a Congregação para os IVC e SVA rejeite o recurso, restará ao demitido a possibilidade de apresentar um último recurso ao Supremo Tribunal da Assinatura Apostólica, dentro de trinta dias após ter sido notificado do decreto pelo Dicastério. Se a Congregação não responder ao recurso, o demitido poderá recorrer à Assinatura Apostólica trinta dias após o término do prazo de três meses após a apresentação do recurso junto ao Dicastério competente.

Por fim, o cân. 700 afirma que o recurso produz efeitos suspensivos, o que significa que a eficácia do decreto de demissão fica suspensa até que o recurso não tenha exaurido o seu iter e, portanto, o religioso permanece como tal até o final do juízo. Consequentemente, se o religioso ainda está no instituto, não poderá ser mandado embora e se já está fora do instituto, deverá ser mantido por ele até a solução definitiva do seu caso. Caso não haja recurso, a demissão produz os efeitos indicados pelos cânn. 701-702, dos quais não nos ocuparemos aqui, pois isso será feito na segunda parte do artigo.

\section{Conclusão}

O instituto jurídico da demissão dos religiosos é uma espécie de "remédio amargo" previsto pela Igreja em favor dos institutos quando se depara com membros que, com uma conduta evidentemente contrária aos valores da própria consagração, afetam a vitalidade do instituto de pertença, da vida religiosa e, portanto, da própria Igreja. Isso não quer dizer que esse instrumento de tutela do bem comum foi colocado "nas mãos" dos institutos, levando-se em conta apenas e tão somente os seus direitos, favorecendo o arbítrio em relação àquele que será demitido. Pelo contrário, pois o legislador, ao emanar uma disciplina sobre a demissão dos religiosos, levou em consideração que o religioso possui uma dignidade que deriva do fato de ser pessoa humana e, ainda mais, consagrada a Deus, de modo particular por meio da profissão religiosa. O respeito à pessoa e a tutela dos valores da vida religiosa são, portanto, dois aspectos que se fazem nitidamente presentes no instituto jurídico da demissão dos religiosos, tenha ela a forma que tiver. 
A tutela dos direitos fundamentais e a salvaguarda dos direitos subjetivos aparece com clareza nos procedimentos previstos pela normativa, particularmente quando se trata da demissão ab homine facultativa que, no caso, se aplicaria também a ausência ilegítima da casa religiosa por ao menos seis meses com a intenção de se subtrair ao poder dos superiores. Não resta dúvida de que todas as garantias previstas traduzem de modo satisfatório os princípios amadurecidos com o Concílio Vaticano II e formulados pelo Sínodo dos Bispos de 1967. O legislador deixou bem claro que é preciso demonstrar não apenas que a ausência do religioso é, de fato, ilegítima, como, também, o animus do religioso e a sua incorrigibilidade. Não raramente uma ausência que no início era legítima, acaba por se transformar em ilegítima, pois o religioso não retorna e, infelizmente, nada se faz. A situação se prolonga por meses e até anos, mas isso não desobriga o Superior maior a proceder conforme a normativa, caso queira, de fato, resolver a situação e o religioso insista em permanecer ausente da casa religiosa de modo ilegítimo.

\section{Bibliografia}

ANDRÉS, D. J. De recursu contra decretum dimissionis suscipiendo a SCRIS (c.700). In: Commentarium pro Religiosis et Missionariis 67 (1986) p. 286-293.

ANDRÉS, D. J. Il diritto dei religiosi. Roma: Ediurcla, 1996.

ANDRÉS, Domingo. Le forme di vita consacrata. Commentario teologico - juridico al Codice di Diritto Canonico. Roma: Ediurcla, 2014 ( $7^{\mathrm{a}} \mathrm{Ed}$.).

ARROBA CONDE, Manuel J. Diritto processuale canonico. Roma: Ediurcla, 2012 ( $6^{\mathrm{a}} \mathrm{Ed}$.).

BAHILLO RUIZ, Teodoro Ángel. Los religiosos ausentes de la casa religiosa según el canon 665. Roma: Pontificia Università Lateranense, 1994.

BEYER, J. Le Droit de la Vie Consacrée. Instituts et Sociétés. Paris: Editions Tardy, 1988. 
BEYER, J. Risposte della Pontificia Commissione per l'autentica interpretazione del Codice: Il decreto di dimissione emesso dal moderatore supremo secondo il c. $700 \mathrm{del} \mathrm{CDC}$, deve essere notificato alla persona prima della conferma da parte della Santa Sede, o dopo tale conferma? In: Vita Consacrata 25 (1989) p. 65-69.

BEYER, Jean. "La dimissione nella vita consacrata". In: Vita Consacrata 28 (1992) p. 157-170.

CALABRESE, Antonio. Istituti di Vita Consacrata e Società di Vita Apostolica. Città del Vaticano: Libreria Editrice Vaticana, 2011 ( $3^{\mathrm{a}} \mathrm{Ed}$.).

CHIAPPETTA, Luigi. Il Codice di Diritto Canonico. Commento giuridico-pastorale. Roma: Edizioni Dehoniane. Vol. 1, 1996.

DE PAOLIS, Velasio. La vita consacrata nella Chiesa. Venezia: Marcianum Press, 2015 ( $2^{\mathrm{a}}$ Ed.).

DI MATTIA, G. Separazione dei membri dall'Istituto e dalla Società di Vita Apostolica. Tipologia e procedura. In: Commentarium pro Religiosis et Missionariis 74 (1993) p. 31-56.

EGAÑA, F. J. Gli IVC e le SVA. Questione canonica: come valutare l'incorreggibilità in ordine alla dimissione di cui al c. $697,3^{\circ}$, quando il religioso, pur promettendo di emendarsi, tuttavia ricade, entro uno spazio di tempo più o meno lungo, negli stessi delitti o in altri simili? In: Vita Consacrata 28 (1992) p. 483-485.

GAMBARI, Elio. I religiosi nel codice. Commento ai singoli canoni. Milano: Ancora, 1986.

GARCÍA MARTÍN, J. Le norme generali del Codex Iuris Canonici. Roma: Ediurcla, 1996.

GHIRLANDA, G. Il diritto nella Chiesa, mistero di comunione. Roma: San Paolo, 1993.

GOMEZ-IGLESIAS, V. El decreto de expulsión del canon 700 y las garantías jurídicas del afectado. In: Ius Canonicum 27 (1987) p. 643-670. 
LLOBELL, J. La conferma del decreto di dimissione del religioso a norma del can. 700. Note sull'ermeneutica degli istituti rivolti all'attuazione del diritto di difesa. In: Ius Ecclesiae 4 (1992) p. 235-252.

LOBINA, G. La separazione dei religiosi dall'Istituto. In: Apollinaris 61 (1983) p. 115-146.

PONTIFICIA COMMISSIO CODICI IURIS CANONICI AUTHENTICE INTERPRETANDO. In: Acta Apostolici Sedis 78 (1986) p. 1323-1324.

PONTIFICIA COMMISSIO CODICI IURIS CANONICI RECOGNOSCENDO. Schema Canonum De Institutis Vitae Consecratae per professionem consiliorum evangelicorum (reservatum). Città del Vaticano: Typis Polyglottis Vaticanis, 1977. 